\title{
The influence of fixed transition modeling on aeroelastic simulations in comparison to wind tunnel experiments
}

\section{Jens Neumann, Diliana Friedewald \& Holger Hennings}

\section{CEAS Aeronautical Journal}

An Official Journal of the Council of European Aerospace Societies

ISSN 1869-5582

Volume 9

Number 3

CEAS Aeronaut J (2018) 9:491-503 DOI 10.1007/s13272-018-0299-y

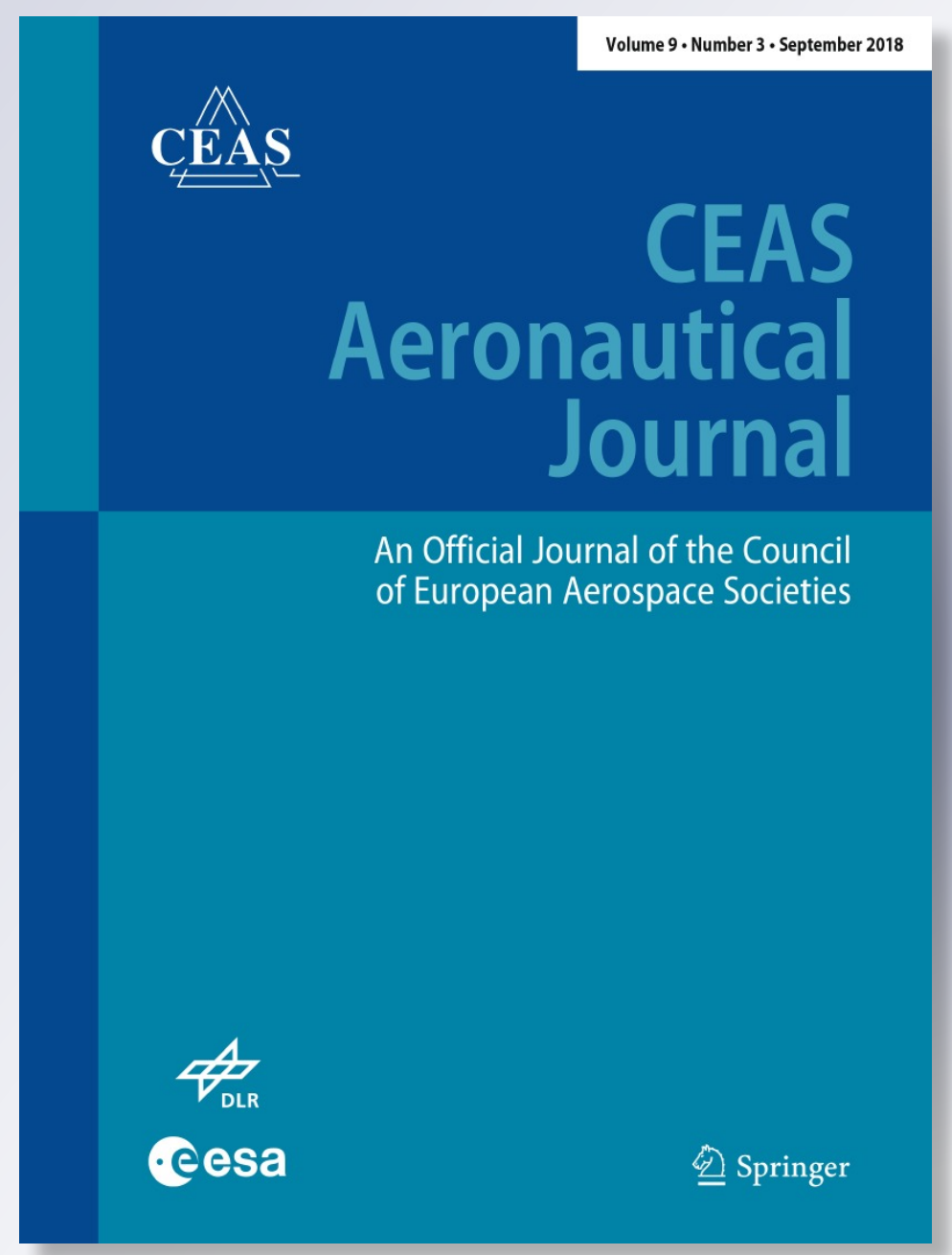

包 Springer 
Your article is protected by copyright and all rights are held exclusively by Deutsches Zentrum für Luft- und Raumfahrt e.V.. This eoffprint is for personal use only and shall not be self-archived in electronic repositories. If you wish to self-archive your article, please use the accepted manuscript version for posting on your own website. You may further deposit the accepted manuscript version in any repository, provided it is only made publicly available 12 months after official publication or later and provided acknowledgement is given to the original source of publication and a link is inserted to the published article on Springer's website. The link must be accompanied by the following text: "The final publication is available at link.springer.com". 


\title{
The influence of fixed transition modeling on aeroelastic simulations in comparison to wind tunnel experiments
}

\author{
Jens Neumann ${ }^{1} \cdot$ Diliana Friedewald $^{1} \cdot$ Holger Hennings ${ }^{1}$ \\ Received: 7 April 2017 / Revised: 28 February 2018 / Accepted: 17 March 2018/Published online: 24 April 2018 \\ (C) Deutsches Zentrum für Luft- und Raumfahrt e.V. 2018
}

\begin{abstract}
This paper presents the results from three-dimensional fluid-structure interaction simulations of an aeroelastic wind tunnel experiment which was conducted in the Transonic Wind Tunnel in Göttingen, Germany in 2013. The experimental setup consisted of two wings: a rectangular NACA0010 wing, which was used as a gust generator, and further downstream a three-dimensional elastic wing representing the outer part of a typical transport-aircraft wing, the so-called 'Aerostabil' wing. Laminar-turbulent boundary layer transition has been tripped to generate turbulent flow. The investigations in this paper are focused on the numerical influence of fixed transition compared to fully turbulent simulations. The effect of the different aerodynamic modeling becomes most obvious for higher angles of attack. Steady aeroelastic simulations including fixed transition modeling show more accurate numerical results than the fully turbulent simulations when compared to experimental data. Moreover, unsteady simulations reveal a significant reduction of unsteady loads for simulations with fixed transition compared to fully turbulent simulations.
\end{abstract}

Keywords Transition tripping · Aeroelasticity · Fluid-structure interaction · Gust experiment · Steady and unsteady aerodynamics $\cdot$ Flow separation $\cdot$ Aerostabil wing

\section{Introduction}

High fidelity methods such as computational fluid dynamics (CFD), finite element methods (FEM) and the coupling of both methods in fluid-structure interaction (FSI) simulations provide the possibility to predict the loads of an aircraft with higher accuracy than traditional methods based on potential theory for example. This improved prediction accuracy can then be used in stability analysis, such as flutter computations, or in load predictions, e.g., due to gusts. A validation of these high-fidelity methods is particularly necessary when flow separation occurs [1], i.e., for high angles of attack and for high Mach numbers. This need can be satisfied using wind tunnel data, which can serve as a reference for these methods. Most of the aerodynamic and aeroelastic wind tunnel experiments

Jens Neumann

jens.neumann@dlr.de

1 German Aerospace Center (DLR), Institute of Aeroelasticity, Bunsenstr. 10, 37073 Göttingen, Germany apply transition tripping on their wing models for the following reasons [2]:

- To enforce turbulent flow and to obtain similar flow conditions between the small-scaled experiment and the aircraft in flight condition.

- To prevent the appearance of a laminar separation bubble in subsonic flow with strong adverse pressure gradients.

- For a better comparison to fully turbulent simulations, because the prediction of the free boundary layer transition is still very complicated.

Though the application of transition tripping in experiments is well established, numerical methods lagged behind for a long time. Experiments with fixed transition are usually compared to fully turbulent simulations. A method of fixed transition modeling was only implemented in 2008 in the DLR TAU-Code [3], by Krumbein [4] and so far, only a few applications of this method are known [5]. The goal of this paper is the comparison between fully turbulent simulations and simulations with a fixed transition modeling for steady and unsteady flow. 
Aeroelastic wind tunnel data serve as a reference for the numerical results.

The paper is structured as follows: at first, an overview of the experimental setup is given. After that, the numerical methods and models are explained in detail. Some special numerical settings like the numerical wind tunnel wall adaption technique will be discussed and a validation of the setup is carried out using boundary layer measurements. Numerical results for the static aeroelastic equilibrium are presented, such as model deformations, local and global aerodynamic characteristics. Finally, the influence of the fixed transition on the unsteady aerodynamic loads will be shown.

\section{Gust response experiment}

The wind tunnel experiment which will serve as a reference for the numerical simulation was performed in the transonic wind tunnel Göttingen (DNW-TWG), Germany.

Figure 1a shows the setup of the gust experiment in the test section of the DNW-TWG. The so-called gust

(a)

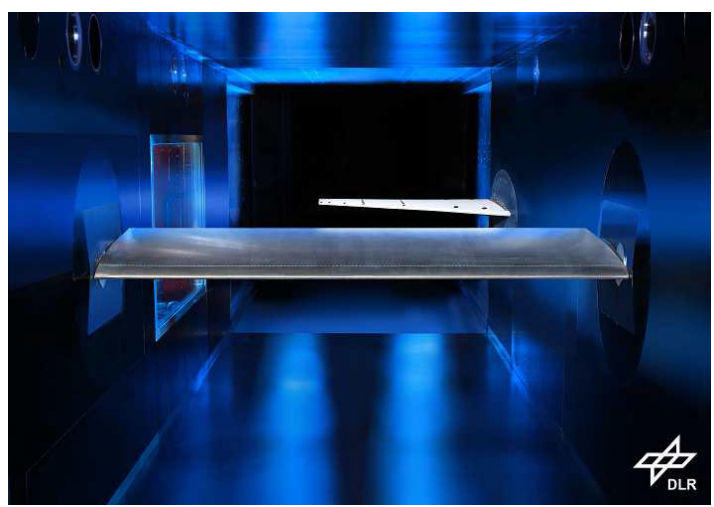

(b)

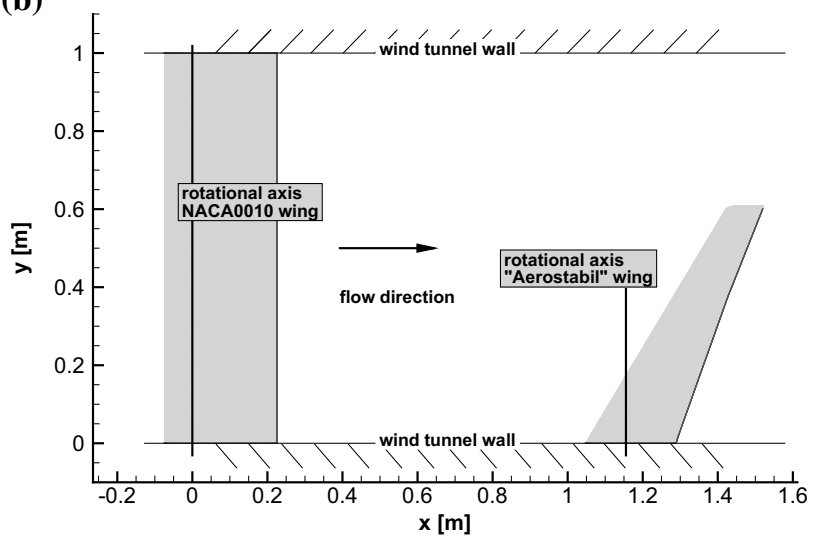

Fig. 1 Arrangement of the gust experiment in the wind tunnel DNWTWG. a Experimental setup. b Sketch of the dimensions generator is located in the front: a 2-D wing with a NACA0010 airfoil section which is mounted on both sidewalls of the wind tunnel. Behind the gust generator, the three-dimensional elastic Aerostabil wing is mounted. This model is an elastic, high-aspect-ratio wing with a supercritical airfoil and represents the outer part of a typical aircraft wing [2]. In Fig. $1 b$ the dimensions of the wing models, their rotational axes and the wind tunnel walls are depicted in the $X-Y$ plane.

Figure $2 \mathrm{a}$ shows the pressure tap sections on the elastic wing Aerostabil and the location of the transition tripping. The height of the tripping was $0.152 \mathrm{~mm}$. For the measurement of the local pressure distribution, the model was instrumented with 93 miniature differential pressure transducers Kulite XCQ-093-5psiD. The pressure transducers are located in three stream-wise rows at $y=0.195$ $\mathrm{m} / 0.264 \mathrm{~m} / 0.405 \mathrm{~m}$. In Fig. 2b the integrated local lift coefficients from the experiment are shown at a Mach number of $\mathrm{Ma}=0.5$. The middle section $(y=0.264 \mathrm{~m})$ leads to the highest local lift. Furthermore, the lift coefficients of the inner and middle section do not show a pronounced maximum value. In the outer section at $y=0.405$ $\mathrm{m}$, the local lift reaches its maximum lift at approximately $\alpha=8.5^{\circ}-9.0^{\circ}$. The first experimental and numerical investigations with this setup were conducted in 2011 [6] and in 2013 [7], where the gust response of the elastic wing was studied.

\section{Fluid-structure interaction simulations}

\subsection{Flow solver with modeling of fixed transition}

The DLR TAU-Code [3] is used for all flow simulations presented here. This code comprises a finite-volume solver that computes the compressible, three-dimensional, timeaccurate Reynolds-averaged Navier-Stokes equations on unstructured or hybrid grids, including several turbulence models, as well as LES and DES models and a transition prediction module. Additionally, the package includes a pre-processor, a grid adaptation module and a grid deformation module [8]. Different interfaces to structural analysis software allow coupled simulations of static and dynamic aeroelastic problems. TAU uses a vertex-centered dual mesh formulation.

For the simulations in this paper, a central scheme with scalar artificial dissipation is employed for the spatial discretization in combination with an explicit three-stage Runge-Kutta scheme. For turbulent closure, the oneequation Spalart-Allmaras turbulence model [9] in its original version is chosen. A local time-stepping scheme [10] is applied for steady computations and an 
Fig. 2 Measurement setup, transition tripping and experimentally obtained lift on the elastic wing model 'Aerostabil'. a Pressure tap sections and transition tripping location. b Measured local lift coefficients (a)

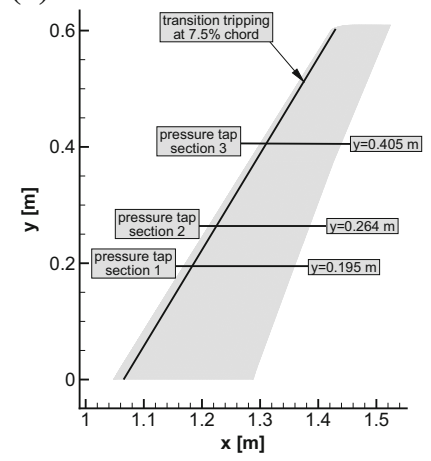

(b)

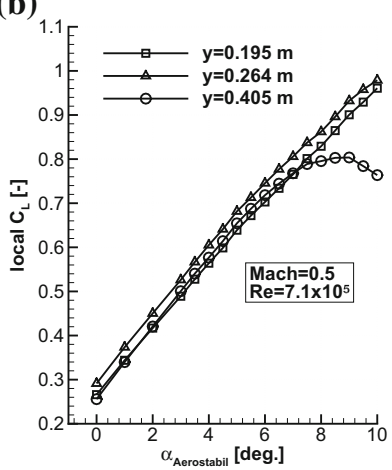

implicit dual time-stepping scheme [11] is used for unsteady time-accurate computations.

For the modeling of the fixed transition, the approach of Krimmelbein is applied [5]. The method allows a laminar region to be defined up to a certain point and enforces turbulent flow behind it. The laminar regions are prescribed by the definition of a polygonal line on the upper and lower surface of the wing. In each cell of the CFD mesh which is located in front of the transition line, the turbulent production terms are set to zero. As in the experimental setup, the numerical transition is fixed to $7.5 \%$ chord of the Aerostabil wing over the complete wing span.

\subsection{Structural solver}

MSC Nastran with its eigenvalue solver SOL103 is applied for the modal analysis. The resulting eigenvalues and eigenvectors are used to describe the structural behavior of the elastic Aerostabil wing in a modal approach.

\subsection{Fluid-structure coupling methodology}

The coupling methodology for the FSI simulations in this paper is based on surface splining with scattered data interpolation and radial basis functions [12-14]. The governing differential equation of motion is solved in modal coordinates and reads:

$$
[I]\{\ddot{q}(t)\}+[\Omega]\{q(t)\}=\left[\tilde{\Phi}_{\mathrm{s}}\right]^{T}\left\{f_{\mathrm{s}}(t)\right\} .
$$

Equation (1) is normalized with the generalized mass matrix using $f_{\mathrm{s}}$ as the external forces acting on the structural degrees of freedom, $\ddot{q}$ as the generalized accelerations and $q$ as the generalized displacements. I denotes the identity matrix. Equation (1) is decoupled regarding each eigenvalue and eigenmode of the structure. The modal matrix $\tilde{\Phi}_{\text {s }}$ contains each eigenmode of the structural model and $\Omega$ is the diagonalized eigenvalue matrix. The structural eigenmodes $\tilde{\Phi}_{\mathrm{s}}$ can be interpolated onto the aerodynamic surface mesh using a spline matrix $H$ [15]. By means of the virtual work, it can be shown that the structural forces $f_{\mathrm{s}}$ can be calculated with the same, but transposed interpolation matrix $H$, from aerodynamic forces $f_{\mathrm{a}}$ :

$$
\left\{f_{\mathrm{s}}\right\}=[H]^{T}\left\{f_{\mathrm{a}}\right\} .
$$

Inserting Eq. (2) in Eq. (1) leads to

$$
\begin{aligned}
\{\ddot{q}(t)\}+[\Omega]\{q(t)\} & =\left[\tilde{\Phi}_{\mathrm{s}}\right]^{\mathrm{T}}\left\{f_{\mathrm{s}}(t)\right\} \\
& =\left[\tilde{\Phi}_{\mathrm{s}}\right]^{\mathrm{T}}[H]^{\mathrm{T}}\left\{f_{\mathrm{a}}(t)\right\} \\
& =\left[H \tilde{\Phi}_{\mathrm{s}}\right]^{\mathrm{T}}\left\{f_{\mathrm{a}}(t)\right\} \\
& =\left[\tilde{\Phi}_{\mathrm{a}}\right]^{\mathrm{T}}\left\{f_{a}(t)\right\} .
\end{aligned}
$$

The expression $H \tilde{\Phi}_{s}=\tilde{\Phi}_{\mathrm{a}}$ in Eq. (3) can be interpreted as the structural eigenmodes on the aerodynamic surface. For the interpolation of the eigenmode matrix $\tilde{\Phi}_{\mathrm{a}}$, the thin plate spline [16] is used as a basis function in the scattered data interpolation. The calculation of the spline matrix $H$ and the interpolation of $\tilde{\Phi}_{\mathrm{a}}$ has to be done only once, as long as mass and stiffness of the structure are constant. Using the relation between physical displacements $u(t)$ and generalized displacements $q(t)$ :

$\{u(t)\}=[\Phi]\{q(t)\}$,

and under the assumption that the aerodynamic forces $f_{\mathrm{a}}$ are time independent, Eq. (3) leads to

$$
\left\{u_{\mathrm{a}}\right\}=\left[\tilde{\Phi}_{\mathrm{a}}\right][\Omega]^{-1}\left[\tilde{\Phi}_{\mathrm{a}}\right]^{T}\left\{f_{\mathrm{a}}\right\} .
$$

Equation (5) can be interpreted as the well-known linear elasticity equation $f=K u$ from structural mechanics, but acting now at the aerodynamic degrees of freedom. The expression $\Phi \Omega^{-1} \Phi^{T}$ in Eq. (5) is the flexibility matrix, $f_{\mathrm{a}}$ are the aerodynamic forces and $u_{\mathrm{a}}$ are the elastic deformations at the aerodynamic degrees of freedom.

The fluid-structure coupling for steady-state problems is done iteratively using a so-called 'conventional serial staggered algorithm' [17]. The iterative process has converged if the difference of the maximum deflection of the model between two consecutive time steps falls below a 
given value. Comparisons between the presented FSI approach and experimental data always showed good agreement [7, 15, 18-20], for subsonic as well as for transonic flow.

\section{Numerical models}

In this section, the numerical models for the CFD simulations and the structural model of the elastic Aerostabil wing will be described shortly. Due to its high stiffness in comparison to the Aerostabil wing, the wing model of the gust generator (NACA0010) has been assumed to be quasirigid and its elastic behavior has been neglected in all simulations.

\subsection{CFD mesh including wind tunnel wall adaption}

The CFD mesh was created with the mesh generator software CENTAUR. The numerical model represents many parts of the real wind tunnel and consists of the chamber, the nozzle, the adaptive test section, the wing models and adapted wind tunnel walls, see Fig. 3. The inflow crosssection has the dimension of $4 \mathrm{~m} \times 4 \mathrm{~m}$ and the outflow cross-section is $1 \mathrm{~m} \times 1 \mathrm{~m}$. The wind tunnel walls as well as the surfaces of the models are defined to be viscous walls in the CFD simulations. Different numbers of hexahedral layers have been used to resolve the corresponding boundary layers. The CFD mesh consists of 10.8 million points and 38.5 million elements.

During an experiment in the DNW-TWG, the upper and lower walls are adapted to realize freestream conditions

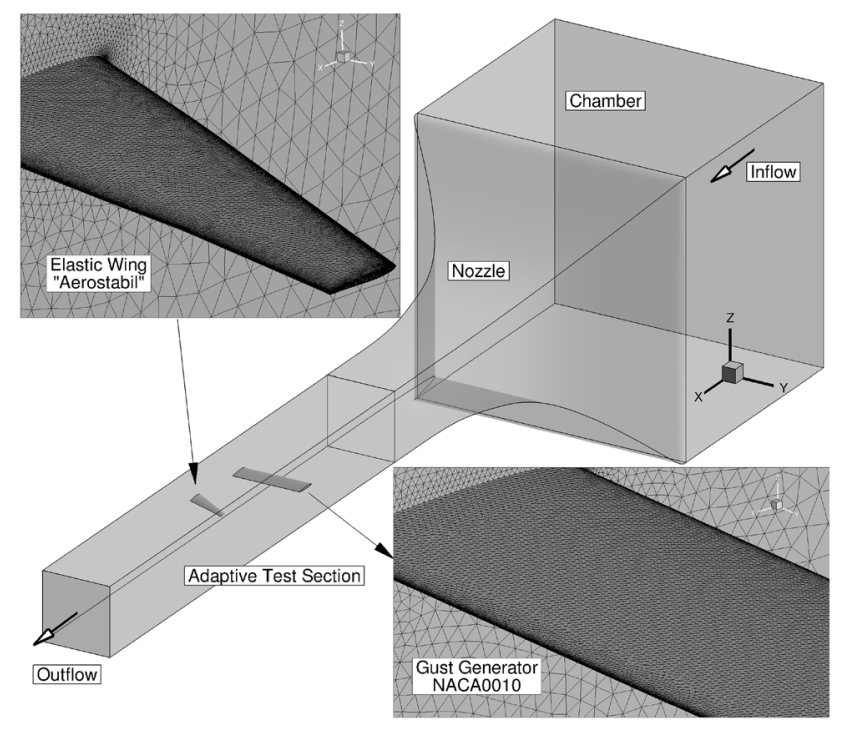

Fig. 3 CFD modeling of the complete wind tunnel including chamber, nozzle, test section and both wing models around the mounted wing models. This is necessary because of the rather small cross-section of the wind tunnel compared to a typical wing chord. To reach a high accuracy, those wall deformations have to be included in the numerical model. In Fig. 4, the numerical and experimental wall adaption is shown for an angle of attack of $\alpha=$ $10.0^{\circ}$. In the rear part of the test section, there are no experimental values available. Hence, a polynomial function is used to return the walls to their original $z$-position.

\subsection{Finite element model}

To represent the structural behavior of the elastic wing, a complex finite element shell model has been developed and compared with measured data from modal tests as well as from static bending and torsion experiments. Both tests have been performed in the wind tunnel under wind-off conditions. The good quality of the numerical model is shown in several publications [7, 21-23]. Overall, 80 modes were used in the coupled simulations, which are obtained from the dynamic analysis of the shell model. The second and the sixth mode shape are depicted in Fig. 5. Especially, in the figure of mode shape number six, it can be observed that the cross-section of the wing deforms significantly. The correct representation of this local deformation is very important for the computation of an accurate pressure distribution.

\section{Validation of the CFD model using boundary layer measurements}

Due to the small cross-section of the wind tunnel, it is important to capture the boundary layer effects correctly in the simulations. To qualify the aforementioned CFD setup and particularly the resolution of the boundary layer at the walls, a comparison with experimental data is carried out. In a recent campaign, the velocity profiles at the wind tunnel walls have been measured in the DNW-TWG without wind tunnel models at different wall positions. The comparison between measured and computed velocity profiles are shown in Fig. 6 at three different $X$-positions of the right wind tunnel wall $(x=-2.17 / 0.0 / 1.04 \mathrm{~m})$, at a

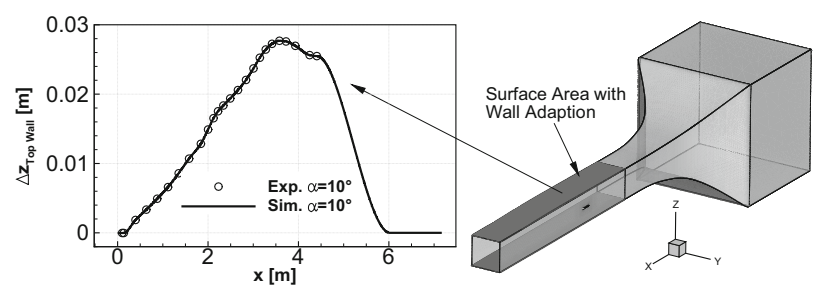

Fig. 4 CFD wind tunnel model including wall adaption for $\alpha=10.0^{\circ}$ 
Mode 2

$f=121.1 \mathrm{~Hz}$
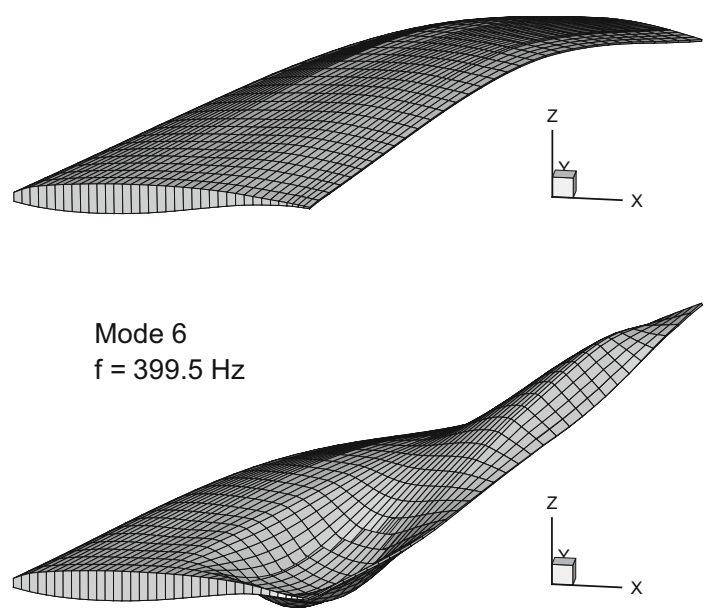

Fig. 5 Second and sixth mode shape of the finite element model of the Aerostabil wing

constant height of $z=0.0 \mathrm{~m}$. This corresponds to the middle of the wind tunnel test section where the wind tunnel models are normally mounted. The inflow Mach number for this investigation was $\mathrm{Ma}=0.5$.

The comparisons in Fig. 6 show that the results are satisfying for all three sections. The measured boundary layer thickness, where $99 \%$ of the freestream velocity is reached, is at $x=-2.17 \mathrm{~m}$, around $\delta_{99, \operatorname{Exp}}=25 \mathrm{~mm}$. The numerical simulation overestimates the experimental value with $\delta_{99, \text { Sim }}=29 \mathrm{~mm}$. In contrast to that, the comparison for $x=0.0 \mathrm{~m}$ shows a very good agreement between experiment and simulation with $\delta_{99, \operatorname{Exp}}=52 \mathrm{~mm}$ against $\delta_{99 . \text { Sim }}=51 \mathrm{~mm}$. At $x=1.04 \mathrm{~m}$, the computations underestimate the experimental boundary layer thickness $\left(\delta_{99, \operatorname{Exp}}\right.$ $=70 \mathrm{~mm}$ against $\delta_{99, \mathrm{Sim}}=62 \mathrm{~mm}$ ). Despite the differences in scalar values, the form of the velocity profiles matches very well, which cannot be taken for granted in such a complex computational setup.
Table 1 Aerodynamic parameters measured in the experiment and used for the computations

\begin{tabular}{ll}
\hline Parameter & Value \\
\hline Mach number $(-)$ & 0.5 \\
Reynolds number & 712123 \\
Reynolds reference length, Aerostabil (m) & 0.183 \\
Reference relation area, Aerostabil $\left(\mathrm{m}^{2}\right)$ & 0.1024 \\
Reference pressure $\left(\mathrm{N} / \mathrm{m}^{2}\right), p_{\infty}$ & 35456.0 \\
Reference velocity $(\mathrm{m} / \mathrm{s}), V_{\infty}$ & 173.24 \\
Angle of attack, NACA0010 $\left(^{\circ}\right)$ & 0.0 \\
Angle of attack, Aerostabil $\left(^{\circ}\right)$ & $0.0-10.0$ \\
$X$-position of the fixed transition, Aerostabil $(-)$ & $7.5 \%$ chord \\
\hline
\end{tabular}

\section{Numerical results: influence of the fixed transition modeling on steady FSI simulations}

The results for steady FSI simulations between angles of attack of the Aerostabil wing of $\alpha=0.0-10.0^{\circ}$ will be presented in the following section. The flow conditions of interest are listed in Table 1.

\subsection{Deformations in static aeroelastic equilibrium}

The prediction of the correct aeroelastic equilibrium state is very important because the steady equilibrium describes the initial condition of the system before any unsteady disturbances in the flow field occur. An incorrect prediction of the steady equilibrium state would result in unreliable unsteady results.

Comparisons of fully turbulent simulations and simulations with fixed transition modeling for global deformations like bending and twist are shown in Fig. 7. The elastic (a)

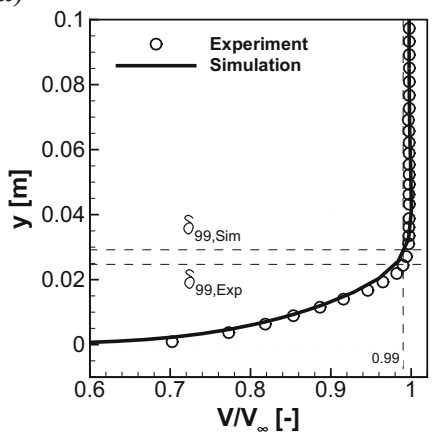

(b)

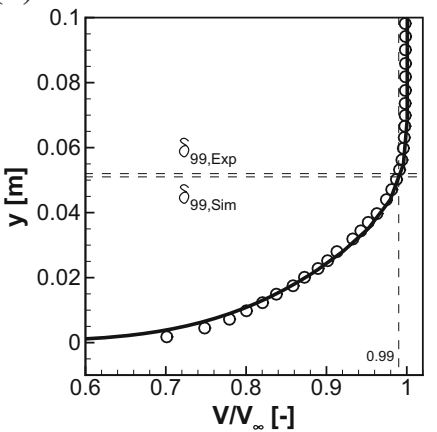

(c)

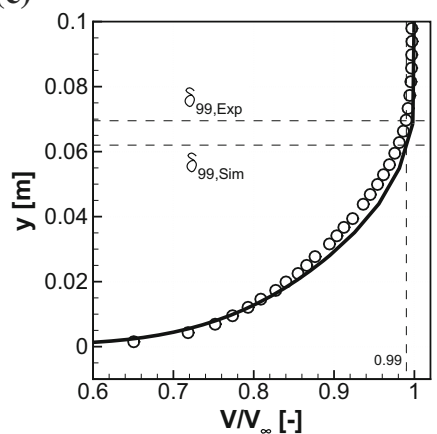

Fig. 6 Comparison of measured and calculated boundary layer profiles for the empty DNW-TWG at Ma $=0.5$ in three cuts of the test section. a $\mathrm{x}=-2.17 \mathrm{~m}$. b $\mathrm{x}=0.0 \mathrm{~m}$. $\mathbf{c} \mathrm{x}=1.04 \mathrm{~m}$. 
deformation of the Aerostabil wing along its span is depicted for an angle of attack of $\alpha=5.0^{\circ}$ and for the highest angle of attack of $\alpha=10.0^{\circ}$.

For the lower angle of attack of $\alpha=5.0^{\circ}$, the results of the fully turbulent simulation and the simulation with fixed transition modeling match perfectly, for the bending deformation as well as for the elastic twist. At the highest angle of attack of $\alpha=10.0^{\circ}$, a completely different deformation behavior of the elastic wing can be observed when fixed transition is included. The elastic deformations are much lower than those for fully turbulent simulations. The bending deformation reduces from max. $\Delta z_{C / 4}=$ $0.0241 \mathrm{~m}$ to max. $\Delta z_{C / 4}=0.0184 \mathrm{~m}$ (by approx. $23.3 \%$ ) and the twist deformation decreases from max. $\Delta \alpha=-$ $1.54^{\circ}$ to max. $\Delta \alpha=-1.2^{\circ}$ (by approximately $22.1 \%$ ).

The diagrams in Fig. 8 show the maximum elastic deformations at the wing tip at each angle of attack from $\alpha$ $=0 \ldots 10.0^{\circ}$. The elastic behavior for fully turbulent simulations and simulations with fixed transition modeling does not differ up to an angle of attack of about $\alpha=6.0^{\circ}$. Then, differences start to occur and grow with an increasing angle of attack. The fixed transition modeling leads to different flow conditions which cause smaller elastic deformations of the wing in the static aeroelastic equilibrium state. Some more local features of the flow will be shown in the following sections.

\subsection{Local pressure distributions in static aeroelastic equilibrium}

As shown in Fig. 2, the elastic wing model was equipped with pressure transducers at three different wing sections. The locally measured pressure $p$ has been transformed to the dimensionless pressure coefficient $C_{p}$ according to Eq. (6):

(a)
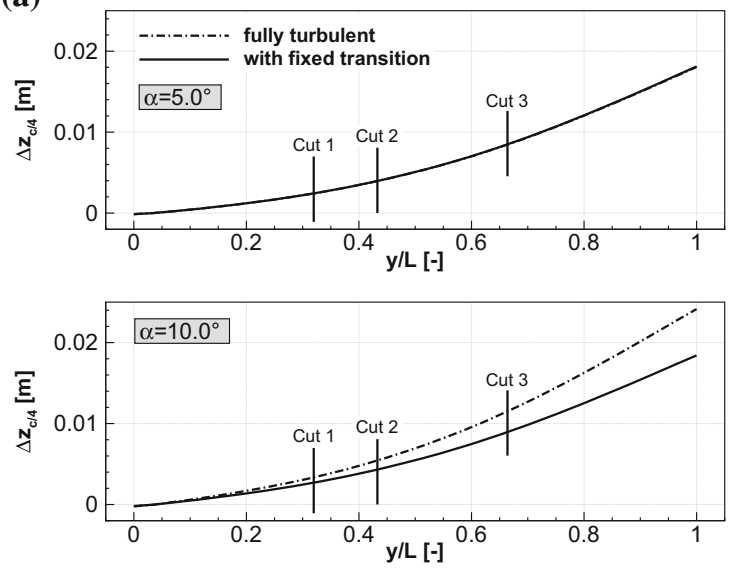

$C_{p}=\frac{p-p_{\infty}}{\frac{\rho}{2} V_{\infty}^{2}}$

To qualify the numerical methods and models, local pressure distributions are compared to experimental values. Numerical and experimental datasets are shown for all three pressure sections at three different angles of attack in Figs. 9, 10 and 11. Figure 9 shows the pressure coefficients at an angle of attack of $\alpha=5.0^{\circ}$. Simulated and measured pressures agree quite well. Only slight differences around the suction peak can be observed. These results correspond very well to the previously discussed trends of the elastic behavior of the wing: for angles of attack between $\alpha=0.0^{\circ}$ and $\alpha=6.0^{\circ}$, the influence of the transition tripping can be neglected.

In Fig. 10, the values for an angle of attack of $\alpha=8.0^{\circ}$ are shown. The differences between the numerical models increase. In all three sections, the strong suction peak vanishes using fixed transition modeling. Almost every single experimental value is predicted more accurately when fixed transition modeling is used. Figure 12 reveals the differences between the simulations at $\alpha=8.0^{\circ}$ in more detail. The fully turbulent simulation results in attached flow, whereas the simulation with fixed transition modeling leads to a laminar separation bubble in the region of the transition tripping. This corresponds to the breakdown of the suction peak in the pressure distribution. Even if the existence of a laminar separation bubble cannot be proven for the experiment, a similar behavior is expected. The results for the highest angle of attack of $\alpha=10.0^{\circ}$ are shown in Fig. 11. A very good agreement between the experiment and the simulation with fixed transition modeling can be observed for the inner two sections. Towards the outer wing, where the flow is completely separated, the results between experiment and simulation differ more strongly.

(b)
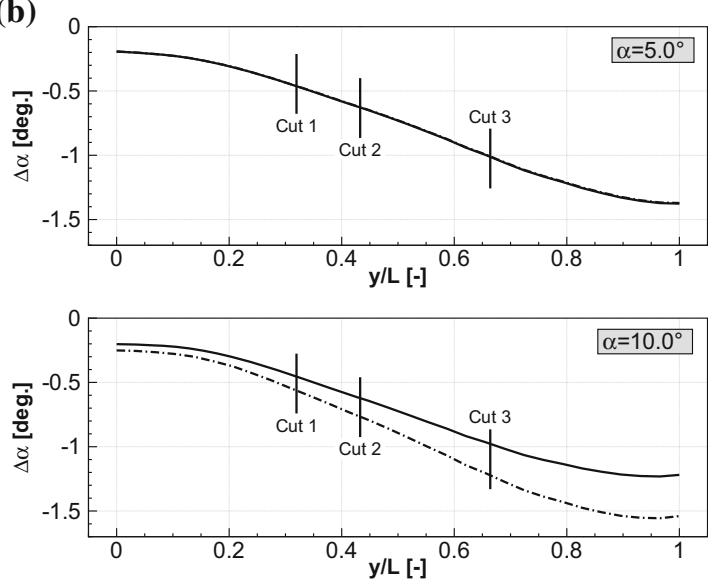

Fig. 7 Influence of fixed transition modeling on the elastic deformation of the Aerostabil wing along the span. a Elastic bending at the c/4-line. b Elastic twist deformation 
Fig. 8 Influence of fixed transition modeling on the maximum elastic deformation of the Aerostabil wing for all angles of attack. a Bending deformation at the wing tip. b Twist deformation at the wing tip (a)

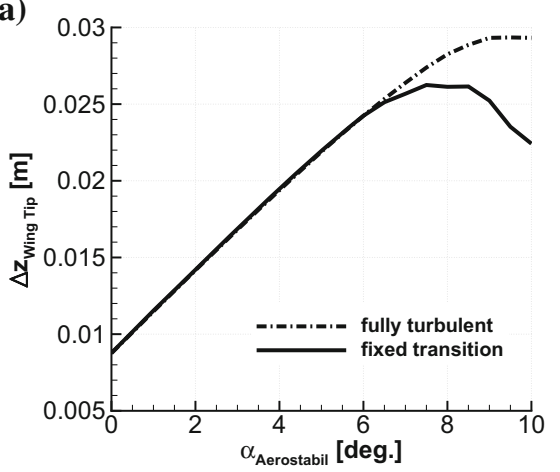

(b)

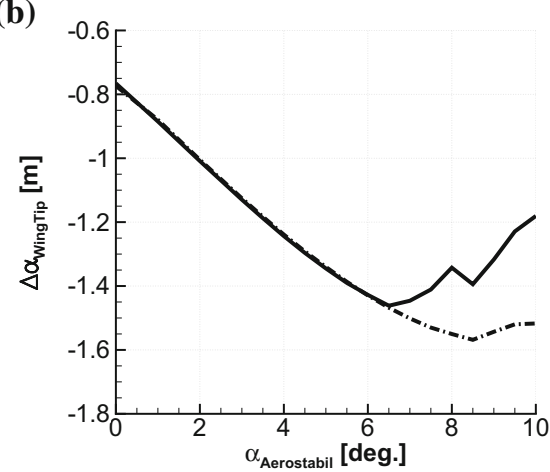

(a)

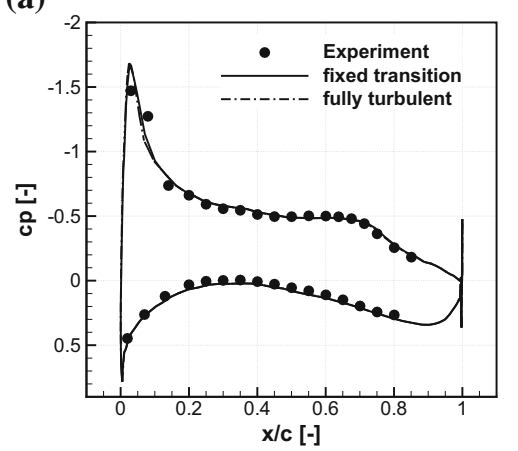

(b)

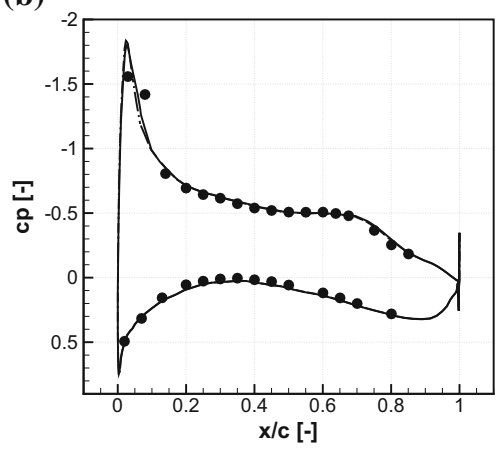

(c)

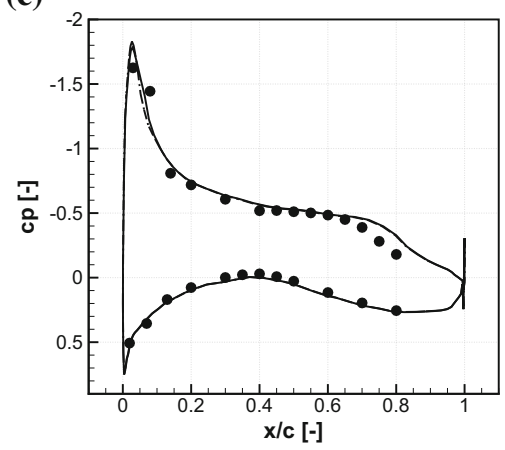

Fig. 9 Measured and calculated dimensionless pressure distribution at an angle of attack of $\alpha=5.0^{\circ}$. a Section cut at $\mathrm{y}=0.195 \mathrm{~m}$. $\mathbf{b}$ Section cut at $\mathrm{y}=0.264 \mathrm{~m}$. c Section cut at $\mathrm{y}=0.405 \mathrm{~m}$

(a)

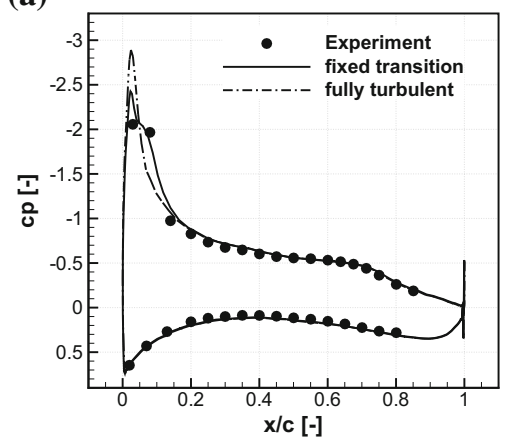

(b)

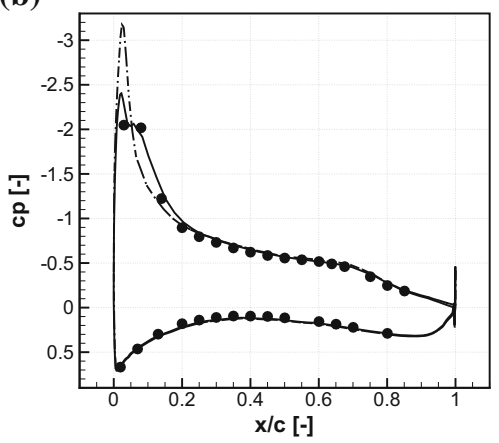

(c)

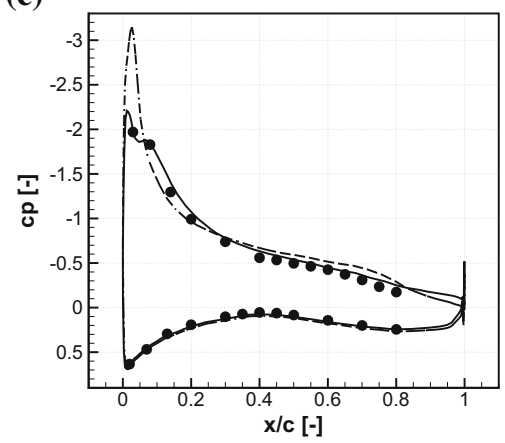

Fig. 10 Measured and calculated dimensionless pressure distribution at an angle of attack of $\alpha=8.0^{\circ}$. a Section cut at $\mathrm{y}=0.195 \mathrm{~m}$. $\mathbf{b}$ Section cut at $\mathrm{y}=0.264 \mathrm{~m}$. c Section cut at $\mathrm{y}=0.405 \mathrm{~m}$

\subsection{Local skin friction distributions in static aeroelastic equilibrium}

Comparisons of the skin friction coefficients for fully turbulent simulations and simulations with fixed transition modeling are shown in Figs. 13 and 14. Depicted are the results for two angles of attack $\left(\alpha=5.0^{\circ}\right.$ and $\left.\alpha=10.0^{\circ}\right)$ in the three sections. The vertical dashed line marks the position of the fixed transition. For the lower side of the wing, there is almost no difference between both numerical models. But on the upper side of the wing, different flow features are already developed at $\alpha=5.0^{\circ}$ : the fully turbulent flow is far from being separated, whereas the simulation with fixed transition shows a small separation bubble just in front of the tripping for the two outer cuts. For $\alpha=10.0^{\circ}$, the differences between the models are retained. The fully turbulent simulation leads to smaller regions of separation than the fixed transition modeling, which causes massive flow separation in all three sections. 
(a)

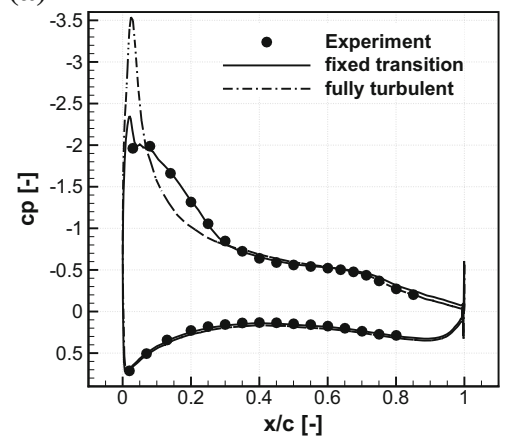

(b)

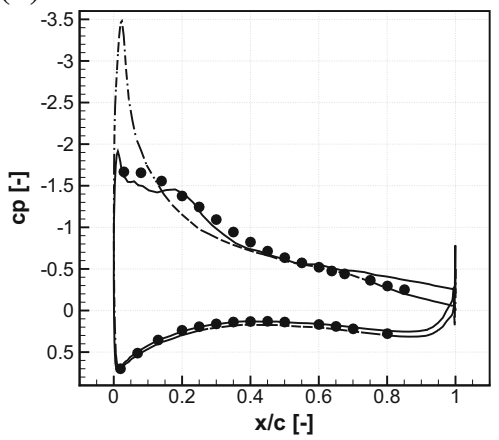

(c)

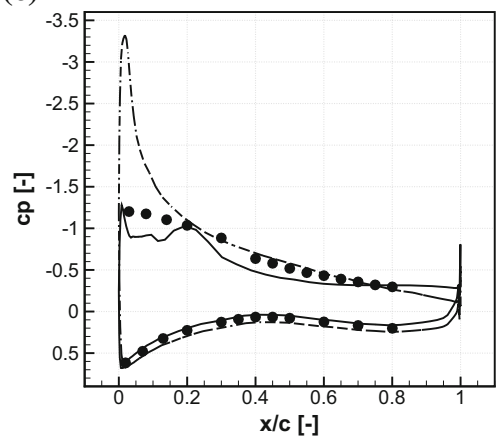

Fig. 11 Measured and calculated dimensionless pressure distribution at an angle of attack of $\alpha=10.0^{\circ}$. a Section cut at $\mathrm{y}=0.195 \mathrm{~m}$. $\mathbf{b}$ Section cut at $\mathrm{y}=0.264 \mathrm{~m}$. c Section cut at $\mathrm{y}=0.405 \mathrm{~m}$

To get an impression of the regions with separated flow on the upper surface of the Aerostabil wing at $\alpha=10.0^{\circ}$, streamlines from the skin friction coefficient have been derived, see Fig. 15. Obviously, the characteristics of the streamlines differ strongly between both solutions. With the fully turbulent simulation, a strong cross-flow occurs in the direction of the wing tip, which is not that pronounced in the modeling with fixed transition. Here, the flow is attached only within a small region at the wing root.

Figure 16 shows the streamlines of the velocity vectors in the vicinity of the wing in the $X-Y$ plane at $y=0.405 \mathrm{~m}$. They confirm the previous findings: in this section cut, the fully turbulent flow is mainly attached, whereas the solution with fixed transition shows flow separation over the complete section cut. Moreover, a recirculation area behind the position of the fixed transition and a large trailing edge recirculation area are formed, which dominate the aerodynamic behavior of the wing and are missing in the fully turbulent solution. Recall that only the definition of the numerical transition point leads to these extremely different flow characteristics. Hence, if the position of the laminar-turbulent transition is known, separated flow at high angles of attack can be predicted on a more accurate level.

(a)

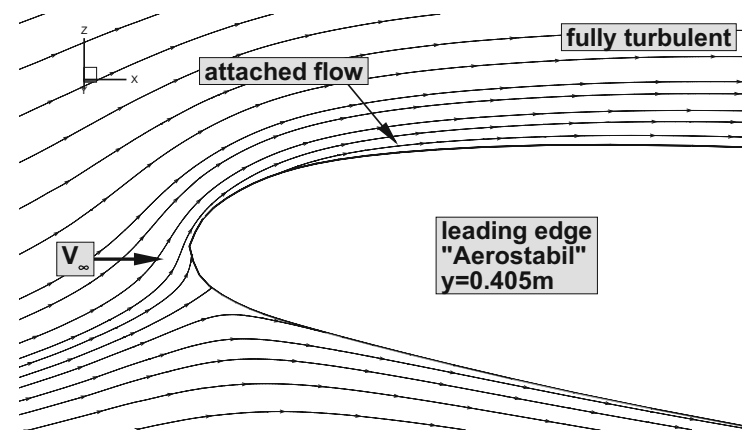

\subsection{Comparison of local lift values in static aeroelastic equilibrium}

For the comparison of the measured and the calculated dimensionless lift $C_{\mathrm{L}}$, the normal force $C_{\mathrm{N}}$ and the tangential force $C_{\mathrm{T}}$ have been integrated from the local pressures $C_{p}$ according to Eqs. (7) and (8),

$$
\begin{aligned}
& C_{\mathrm{N}}=\oint C_{p} \mathrm{~d} x, \\
& C_{\mathrm{T}}=\oint C_{p} \mathrm{~d} y .
\end{aligned}
$$

The lift acts perpendicular to the incoming flow

$$
C_{\mathrm{L}}=C_{\mathrm{N}} \cos \alpha-C_{\mathrm{T}} \sin \alpha \text {. }
$$

For a fair comparison between numerical and experimental data, only those numerical pressures are chosen for the integration that correspond to the positions where the experimental pressure transducers are located. Local aeroelastic lift polars are shown for all three section cuts in Fig. 17. A better match with the experimental values is obtained for the simulations with fixed transition modeling. Basically, the same trends that were found in the pressure

(b)

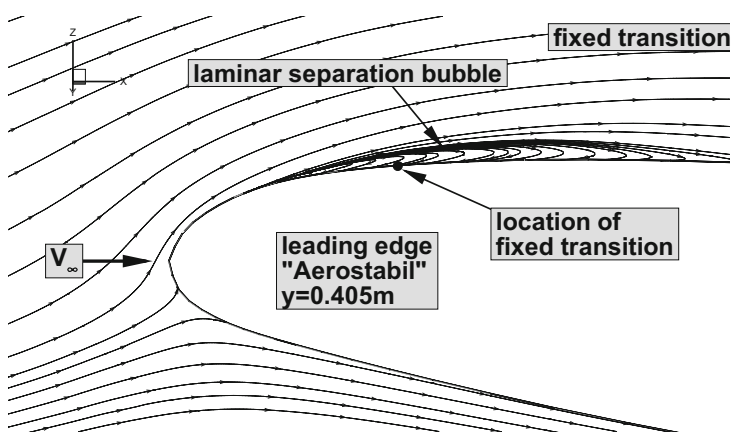

Fig. 12 Local influence of fixed transition on the upper side of the wing at an angle of attack of $\alpha=8.0^{\circ}$. a Attached flow, fully turbulent simulation. b Local separation bubble, simulation with fixed transition 
(a)

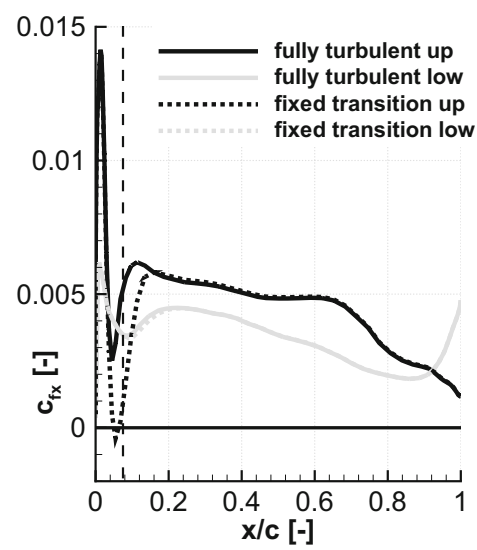

(b)

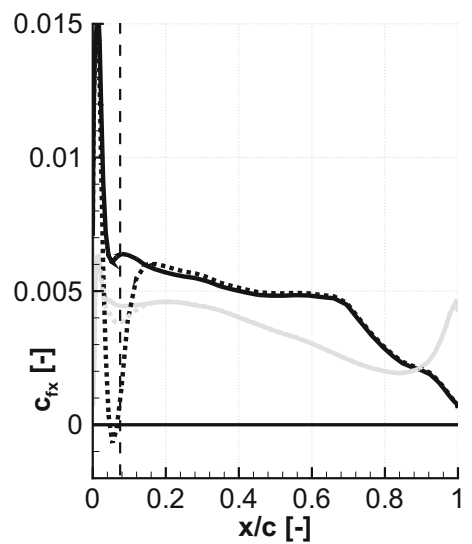

(c)

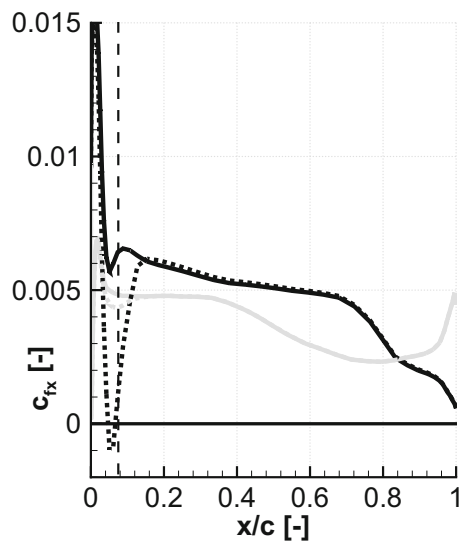

Fig. 13 Influence of fixed transition modeling on the skin friction coefficient $C_{\mathrm{fx}}$ at an angle of attack of $\alpha=5.0^{\circ}$. The dashed vertical line marks the position of the fixed transition. a Section cut at $y=0.195 \mathrm{~m}$. b Section cut at $\mathrm{y}=0.264 \mathrm{~m}$. c Section cut at $\mathrm{y}=0.405 \mathrm{~m}$

(a)

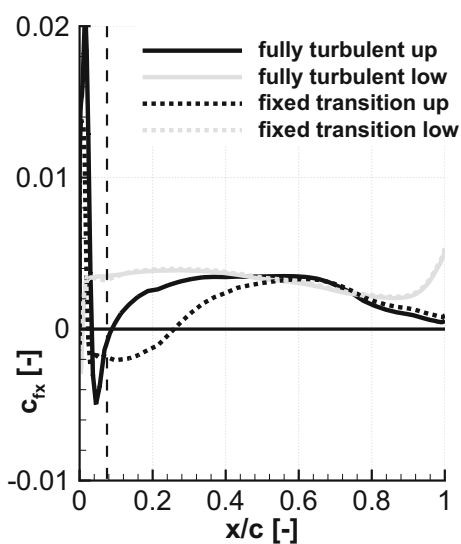

(b)

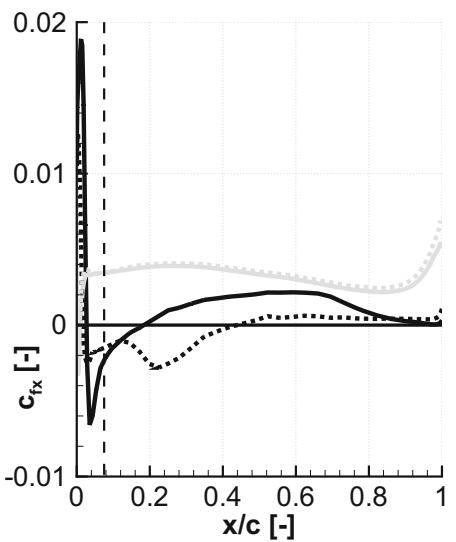

(c)

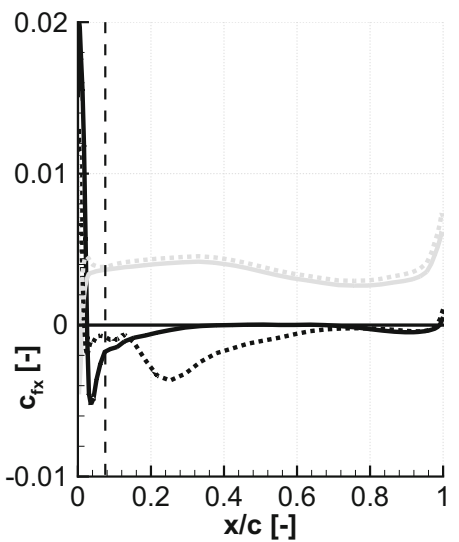

Fig. 14 Influence of fixed transition modeling on the skin friction coefficient $C_{\mathrm{fx}}$ at an angle of attack of $\alpha=10.0^{\circ}$. The dashed vertical line marks the position of the fixed transition. a Section cut at $\mathrm{y}=0.195 \mathrm{~m}$. b Section cut at $\mathrm{y}=0.264 \mathrm{~m}$. c Section cut at $\mathrm{y}=0.405 \mathrm{~m}$

distribution can be emphasized with the integrated local lift values: simulations with fixed transition modeling come closer to the experimental data. Nevertheless, a premature breakdown of the lift can be seen in all three sections. Especially in the outer wing section at the highest angle of attack of $\alpha=10.0^{\circ}$, some effects were not captured well, see Fig. 17c. The same observation was already made for the comparison of the pressure distributions in Fig. 11.

\section{Numerical results: influence of the fixed transition modeling on unsteady FSI simulations}

To find out the influence of the fixed transition modeling on the unsteady aeroelastic behavior of the Aerostabil wing, the wing is excited by disturbance velocities that are generated by a pitching motion of the upstream NACA0010 wing, recall Fig. 1. Each excitation signal in this numerical investigation is a single pulse in form of a (1-cos) input to the actuation of the NACA0010 wing, see Fig. 18. The shape of the pulse was chosen to create a broadband excitation of the whole system in a frequency range from 0 to $100 \mathrm{~Hz}$, corresponding to a reduced frequency of 0-1, see Fig. 19. Frequency response functions (FRF), that relate the observed transient response of the Aerostabil wing tip to the excitation signal, are compared for two turbulence-modeling techniques: fully turbulent simulations and simulations with fixed transition.

The flow conditions for the unsteady cases are the same as those listed in Table 1. The unsteady time step size is set to $2 \times 10^{-4} \mathrm{~s}$, which roughly corresponds to a traveled distance of $12 \%$ chord of the NACA0010 wing per time step. Similar kinds of gust excitations and time step sizes 

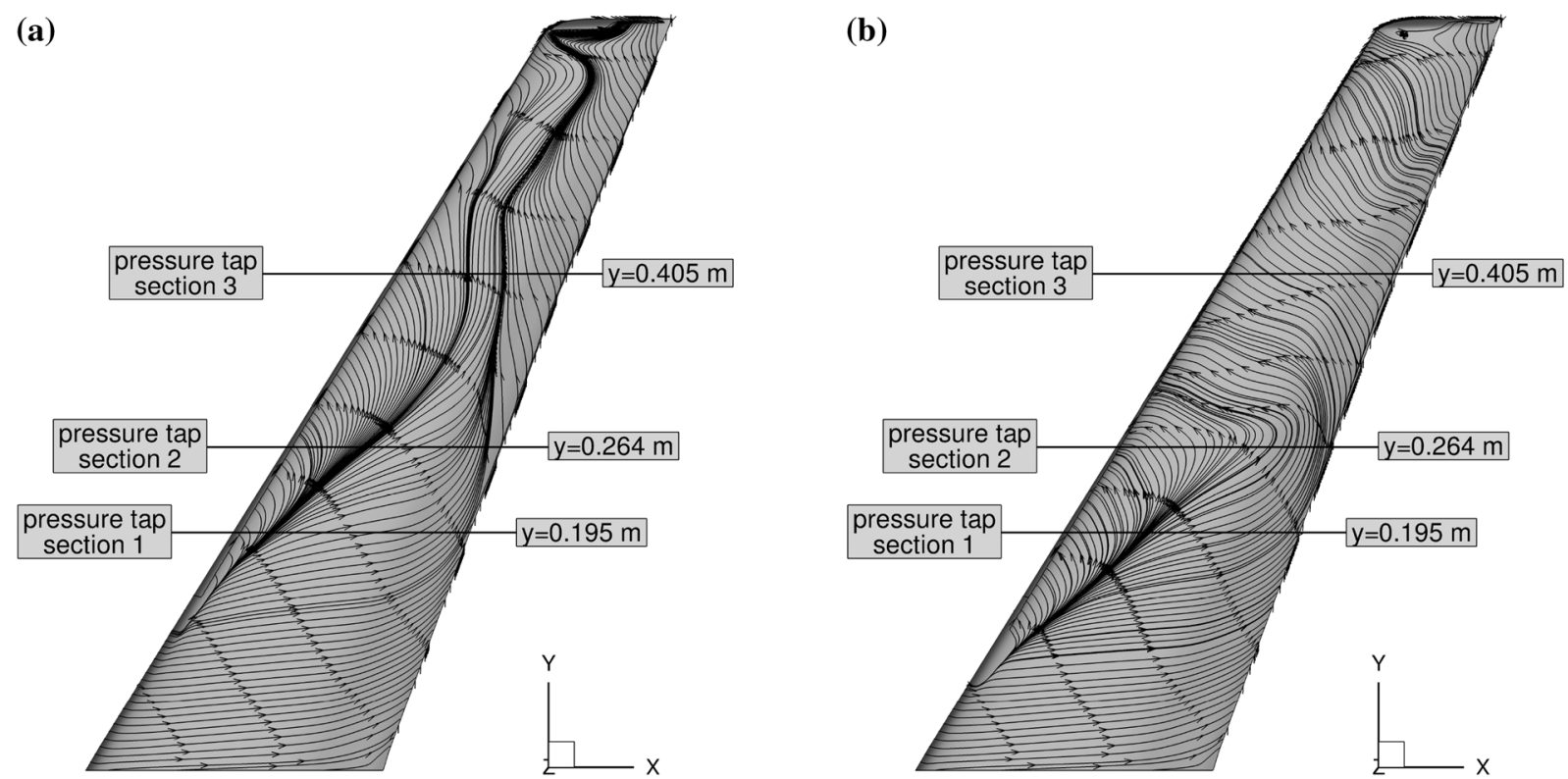

Fig. 15 Streamlines of the dimensionless skin friction coefficient $C_{\mathrm{f}}$ for an angle of attack of $\alpha=10.0^{\circ}$. a Fully turbulent simulation. b Simulation with fixed transition modeling

(a)

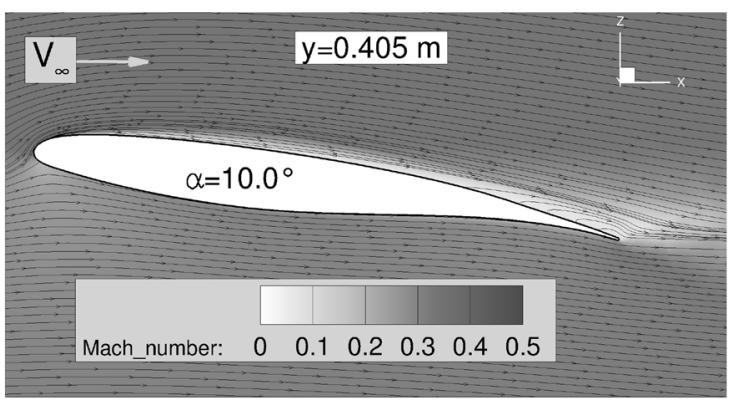

(b)

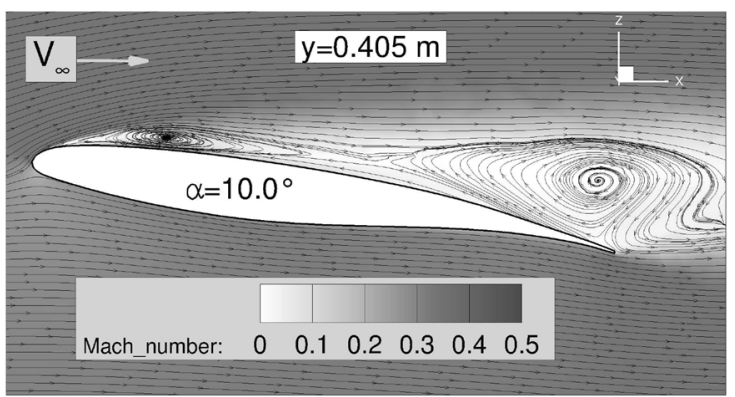

Fig. 16 Mach number distribution and streamlines of the velocity vectors in the vicinity of the Aerostabil wing for an angle of attack of $\alpha=10.0^{\circ}$. a Fully turbulent simulation. b Simulation with fixed transition modeling

(a)

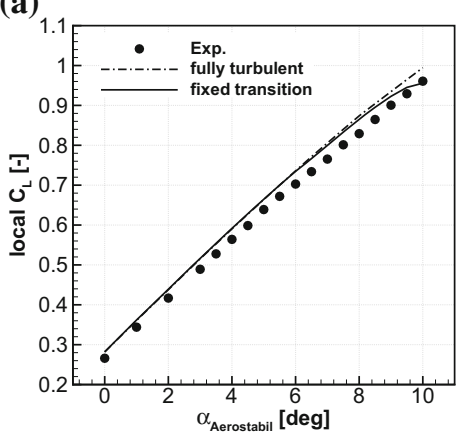

(b)

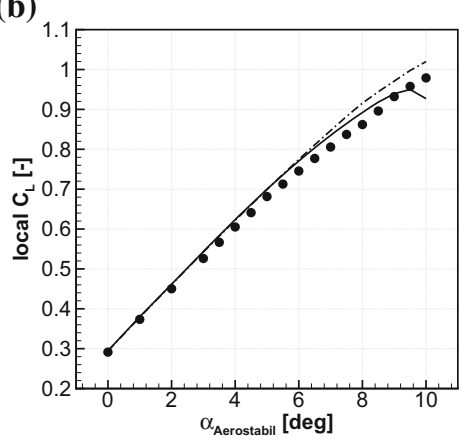

(c)

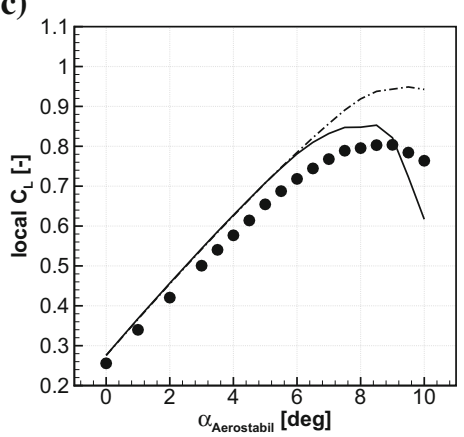

Fig. 17 Measured and calculated local lift polars at the three different sections of the Aerostabil wing. a Section cut at $\mathrm{y}=0.195 \mathrm{~m}$. b Section cut at $\mathrm{y}=0.264 \mathrm{~m}$. c Section cut at $\mathrm{y}=0.405 \mathrm{~m}$ 


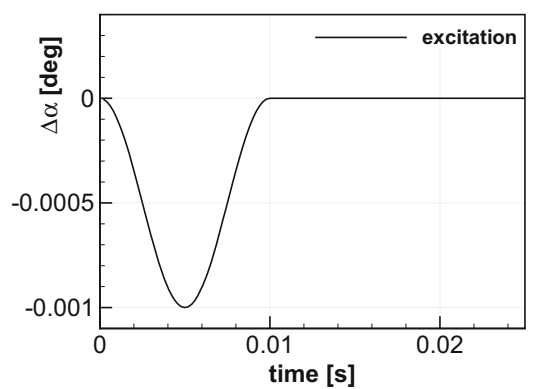

Fig. 18 '1-cos' excitation signal of the NACA0010 wing over time

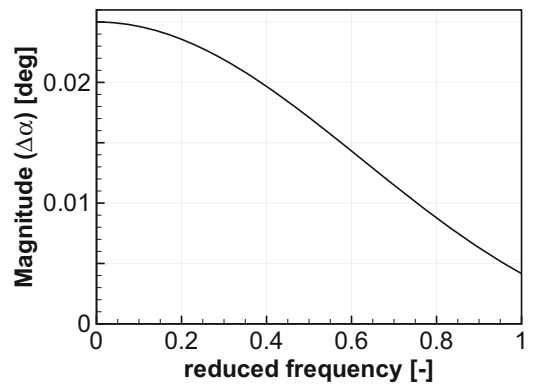

Fig. 19 Frequency spectrum of the ' 1 -cos' excitation signal

are already used in previous computations [7] and show a good agreement with unsteady experimental data.

For the unsteady cases that are considered in this paper, the steady angle of attack of the Aerostabil wing is set to $5^{\circ}$ and $10^{\circ}$, respectively. The maximum excitation amplitude of the NACA0010 wing is $0.001^{\circ}$, see Fig. 18, which leads to vertical velocity perturbations at the Aerostabil wing in the order of $v_{z} \approx 8.0 \times 10^{-4} \mathrm{~m} / \mathrm{s}$. It is important for the identification of the FRF that the excitation amplitude is small, and therefore, leads to responses that are still in the linear range. The principle of superposition should not be violated.

The resulting deflection at the wing tip over time and the corresponding complex-valued FRFs $H(j \omega)$ are depicted in Figs. 20 and 21 for both steady angles of attack. The FRFs are calculated using the Fourier-transformed time signals of the deflection at the wing tip as the system's output signal $\Delta z=y(t) \rightarrow Y(j \omega)$ and the excitation signal of the NACA0010 wing as the system's input signal $\Delta \alpha=x(t) \rightarrow$ $X(j \omega)$ according to:

$$
H(j \omega)=\frac{Y(j \omega)}{X(j \omega)}
$$

It is hard to distinguish the results of both types of simulation for the lower angle of attack, see Fig. 20. As in the steady cases, the fixed transition modeling does only show minor influences on the $\Delta z$ deflection, since the flow is attached for both simulations and the local flow fields are very similar, see Figs. 9 and 13. Characteristic curves of damped oscillations are shown in Fig. 20a. The eigenmodes of the underlying structural system are revealed in Fig. 20b. The reduced frequencies of 0.28 and 0.81 correspond to the first and second eigenfrequencies (42 and $122 \mathrm{~Hz}$ ) of the coupled aeroelastic system. Moreover, the kinks in the FRF at a reduced frequency of approximately 0.95 show an acoustic wind tunnel resonance of the DNWTWG, which leads to a sudden drop of magnitude and phase $[24,25]$. As expected, the FRFs of the fully turbulent solution and the solution with fixed transition for $\alpha=10^{\circ}$ differ more strongly from each other. The deviations in the unsteady time history of the deflection and the deviations in the transfer functions $\partial z / \partial \alpha$ have their origin in the already fundamentally different steady flow fields. Nevertheless, overall features of the solution as the excitation of the first two structural mode shapes or the acoustic wind tunnel resonance are still contained in both types of flow. The resonance peaks for the solution with fixed transition are shifted to slightly higher frequencies. Moreover, derivatives and deflection amplitudes reach a lower absolute level. The maximum deflection amplitude for the fully turbulent simulation is approximately 53\% larger than the maximum deflection for the simulation with fixed transition modeling, see Fig. 21a.

Hence, judging from a perspective of those two test cases, the aeroelastic system including fixed transition (a)

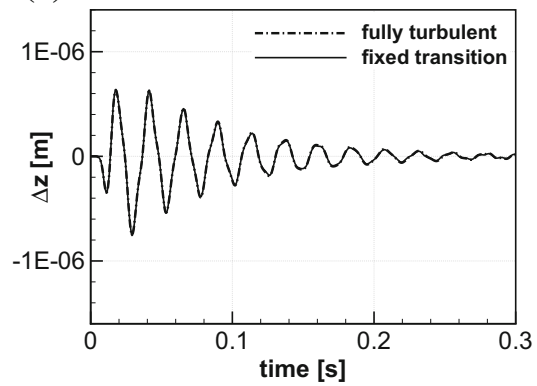

(b)

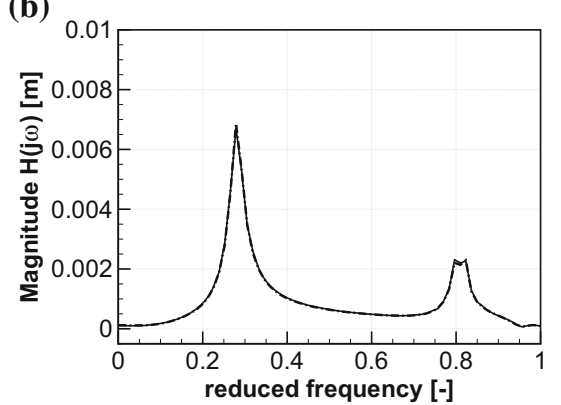

(c)

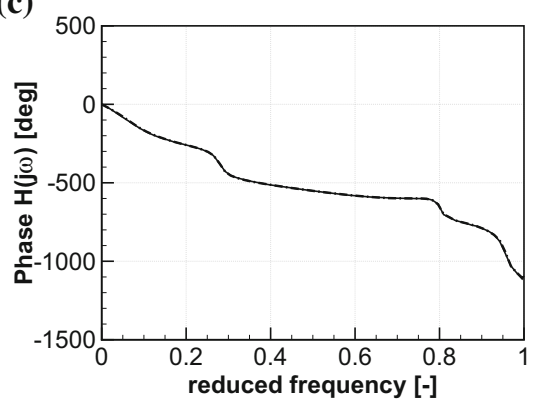

Fig. 20 Influence of the fixed transition modeling on the transfer function of the local displacement $\Delta z$ at the wing tip for a steady angle of attack of $\alpha=5.0^{\circ}$. a Time signal of $\Delta z$. b Magnitude of $H(j \omega)$. c Phase of $H(j \omega)$ 
(a)

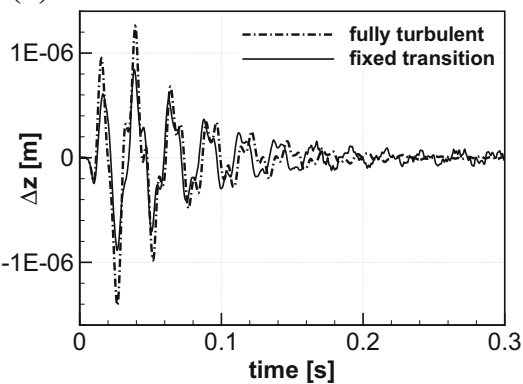

(b)

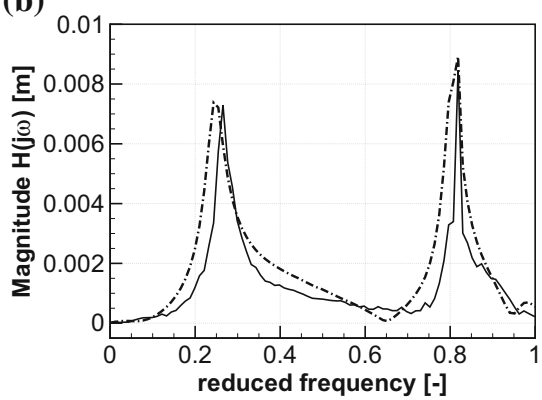

(c)

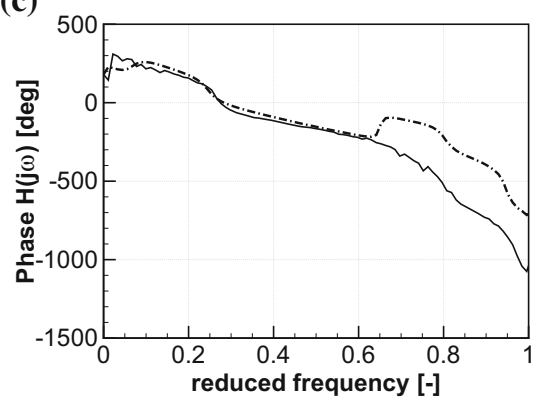

Fig. 21 Influence of the fixed transition modeling on the transfer function of the local displacement $\Delta z$ at the wing tip for a steady angle of attack of $\alpha=10.0^{\circ}$. a Time signal of $\Delta z$. b Magnitude of $H(j \omega)$. c Phase of $H(j \omega)$

modeling results in different dynamic properties compared to the aeroelastic system based on fully turbulent simulations and so might also lead to different aeroelastic stability limits.

\section{Conclusion}

The investigations in this paper were focused on the influence of the fixed transition tripping used in the experiment and its consideration in the simulation in comparison to fully turbulent FSI simulation. The numerical results have been compared to locally measured pressure coefficients and local aeroelastic lift polars. It could be shown that the numerical prediction of separated flow conditions at higher angles of attack is significantly improved by using fixed transition modeling.

- The influence of fixed transition tripping strongly depends on the angle of attack: the higher the angle of attack, the bigger the impact of the fixed transition.

- Numerically fixed transition leads to a laminar separation bubble and at higher angles of attack to massive separation in contrast to attached flow in fully turbulent simulations.

- In unsteady simulations, the numerical modeling including fixed transition influences the eigen frequencies of the coupled aeroelastic system while preserving the overall dynamics of the system.

To conclude, when transition tripping has been used on wind tunnel models in experiments, then it should always be used in the simulation, too. Otherwise, important physical aspects of the flow cannot be captured.

What has not yet been studied is the influence of the turbulence model in combination with fixed transition for example. It is expected that slightly different results occur, especially for the high angles of attack that include flow separation. However, qualitatively, the trends should be the same as for the computations shown here. A more detailed study concerning the influence of turbulence modeling on the fixed transition will be the scope of future work.

Acknowledgements This work was funded by the DLR programmatic research in the project 'ALLEGRA'. The authors would like to thank the experimental team from the Institute of Aeroelasticity, particularly H. Mai, B. Lütke, A. Hebler and J. Lübker for the thorough preparation of the experimental data. Thank you also to all the colleagues not mentioned who have aided this work and made substantial contributions. Furthermore, special thanks goes to J. Dillinger for preparing and providing the finite element model of the elastic wing 'Aerostabil'.

\section{References}

1. Klein, A., Lutz, T., Krämer, E., Richter, K., Gardner, A.D., Altmikus, A.R.M.: Numerical comparison of dynamic stall for two-dimensional airfoils and an airfoil in the DNW-TWG. J. Am. Helicopter Soc. 57, 1-13 (2012)

2. G. Dietz, G. Schewe, F. Kießling, M. Sinapius. Limit-cycle oscillation experiment at a transport aircraft wing model. In: Proceedings of the International Forum on Aeroelasticity and Structural Dynamics (IFASD), Amsterdam, The Netherlands, June 4-6 (2003)

3. T. Gerhold, M. Galle, O. Friedrich, J. Evans. Calculation of complex three-dimensional configurations employing the DLR TAU-code. In: 35th Aerospace Sciences Meeting and Exhibit, AIAA Paper, vol. 0167 (1997)

4. Krumbein, A.: $e^{n}$ transition prediction for $3 \mathrm{~d}$ wing configurations using database methods and a local, linear stability code. Aerosp. Sci. Technol. 12, 592-598 (2008)

5. Krimmelbein, N., Radespiel, R.: Transition prediction for threedimensional flows using parallel computation. Comput. Fluids 38, 121-136 (2009)

6. H. Mai, J. Neumann, H. Hennings. Gust response: a validation experiment and preliminary numerical simulations. In: Proceedings of the International Forum on Aeroelasticity and Structural Dynamics (IFASD), Paris, vol. 051 (2011)

7. Neumann, J., Mai, H.: Gust response: simulation of an aeroelastic experiment by a fluid-structure interaction method. J. Fluids Struct. 38, 290-302 (2013)

8. T. Gerhold, J. Neumann. The parallel mesh deformation of the DLR TAU-Code. In: C. Tropea, S. Jakirlic, H.-J. Heinemann, R. Henke, H. Hönlinger, editors, New Results in Numerical and Experimental Fluid Mechanics VI, vol. 96 of Notes on Numerical Fluid Mechanics and Multidisciplinary Design, pp. 162-169. Springer, 2007 
9. P.R. Spalart, S.R. Allmaras. A one-equation turbulance model for aerodynamic flows. In: Technical Report, American Institute of Aeronautics and Astronautics AIAA, 30th Aerospace Sciences Meeting and Exhibit, Reno, NV, USA (1992)

10. Jameson, A., Schmidt, W., Turkel, E.: Numerical solutions of the Euler equations by finite volume methods using Runge-Kutta time-stepping schemes. In: 14th Fluid and Plasma Dynamics Conference, Palo Alto, CA, USA, AIAA-Paper 81-1295, vol. 81-1259 (1981)

11. Jameson, A.: Time dependent calculations using multigrid, with applications to unsteady flows past airfoils and wings. In: 10th Computational Fluid Dynamics Conference, Honolulu, HI, USA, June 24-26, 1991, AIAA-Paper 91-1596 (1991)

12. Schaback, R.: Creating surfaces from scattered data using radial basis functions. In: Daehlen, M., Lynche T., Schumaker L.L. (eds.) Mathematical Methods in CAGD III, pp. 1-21 (1995)

13. A. Beckert. Ein Beitrag zur Strömungs-Struktur-Kopplung für die Berechnung des aeroelastischen Gleichgewichtszustandes. Ph.D. thesis (in German), University of Braunschweig (1997)

14. Gneiting, T.: Radial positive definite functions generated by euclid's hat. J. Multivar. Anal. 69, 88-119 (1999)

15. Neumann, J., Krüger, W.: Coupling strategies for large industrial models. In: Kroll, N., Radespiel, R., van der Burg, J.W., Sorensen, K. (eds.) Computational Flight Testing. Notes on Numerical Fluid Mechanics and Multidisciplinary Design, vol. 123, pp. 207-222. Springer, Berlin, Heidelberg (2013). https:// doi.org/10.1007/978-3-642-38877-4

16. Harder, R.L., Desmarais, R.N.: Interpolation using surface splines. J. Aircr. 9(2), 189-191 (1972)

17. Farhat, Ch., Lesoinne, M.: Fast staggered algorithms for the solution of three-dimensional nonlinear aeroelastic problems. In: Technical Report R-822, AGARD SMP Meeting on "Numerical Unsteady Aerodynamic and Aeroelastic Simulation (1997)
18. Beckert, A., Wendland, H.: Multivariate interpolation for fluidstructure-interaction problems using radial basis functions. Aerosp. Sci. Technol. 5, 125-134 (2001)

19. Neumann, J., Nitzsche, J., Voß, R.: Aeroelastic analysis by coupled non-linear time domain simulation. In: Specialist's Meeting on Advanced Aeroelasticity, Loen, Norway, Volume (RTO-AV-154), number RTO-AV-154 (2008)

20. Neumann, J., Ritter, M.: Steady and unsteady aeroelastic simulations of the HIRENASD wind tunnel experiment. In: Proceedings of the International Forum on Aeroelasticity and Structural Dynamics (IFASD), Seattle, WA, USA, vol. 132 (2009)

21. Stickan B., Dillinger, J.: Coupled CFD-CSM simulations of the Aerostabil windtunnel experiments, considering sophisticated structural modeling. In: Proceedings of the 17th DGLR/STAB Symposium (2010)

22. Stickan, B., Dillinger, J.: Steady and unsteady simulations of Aerostabil windtunnel experiments. In: International Forum on Aeroelasticity and Structural Dynamics (IFASD), Paris, vol. 157 (2011)

23. Stickan, B., Dillinger, J., Schewe, G.: Computational aeroelastic investigation of a transonic limit-cycle-oscillation experiment at a transport aircraft wing model. J. Fluids Struct. 49, 223-241 (2014)

24. H. Försching and R. Voß. Adaptation for unsteady flow. Technical report, AGARD Advisory Report on Wind Tunnel Adaptation AR-269, Chapter 7 (1989)

25. Kaiser, Ch., Nitzsche, J.: Numerical modeling of wind tunnel walls for the investigation of oscillating airfoils. In: Dillmann, A., Heller, G., Krämer, E., Wagner, C., Breitsamter, Ch. (eds.) New Results in Numerical and Experimental Fluid Mechanics X. Notes on Numerical Fluid Mechanics and Multidisciplinary Design, vol. 132, pp. 457-465. Springer, Switzerland (2016). https://doi.org/10.1007/978-3-319-27279-5 